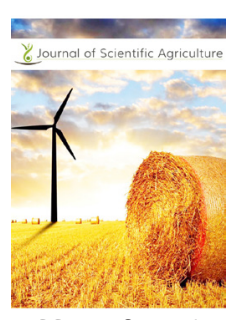

ISSN: $2184^{-0} 0261$
Received: August 25, 2021 Revised: January 17, 2022 Accepted: January 20, 2022 Published: February 25, 2022

*Corresponding author: Desta Abebe Belete E-mail: desta.ab12@gmail.com

\section{Correlation and path coefficient studies for yield and its components of upland rice (Oryza sativa L.) in North Western Ethiopia}

\author{
Desta Abebe Belete ${ }^{1 *}$, Atsedemariam Tewachew ${ }^{2}$, Mulugeta Bitew $^{3}$, \\ Tafere Mulualem ${ }^{1}$
}

${ }^{1}$ Ethiopian Institute of Agricultural Research, Pawe Agricultural Research Center, P.O. Box, 25, Pawe, Ethiopia, ${ }^{2}$ Ethiopian Institute of Agricultural Research, Fogera Rice Research and Training Center, P.O. Box, 190, Wereta, Ethiopia, ${ }^{3}$ Ethiopian Institute of Agricultural Research, Debre Markos Agricultural Research Center, P.O. Box 357, Debre Markos, Ethiopia

\begin{abstract}
Rice is the major source of calories and third largest crop after maize and wheat by productivity. The aim of the present study was to determine the correlations between grain yield and its contributing traits and to measure the direct and indirect effects of those traits on grain yield in upland rice. Sixteen upland rice genotypes were tested using RCBD with three replications at Pawe district (on station and on farm) during 2016/2017 main cropping season. The estimates of genotypic and phenotypic correlation coefficients between nine characters were computed and also the direct and indirect effects. The results obtained indicated that estimates of genotypic correlation coefficients between nine characters were generally different in sign but higher in magnitude than the corresponding phenotypic correlation coefficients. Days to maturity and plant height were showed strong positive and significant phenotypic and genotypic correlations with days to $50 \%$ heading at on farm level. Whereas, thousand seed weight was exhibited strong positive and significant phenotypic and genotypic correlations with davs to $50 \%$ heading followed by panicle length at on station level. The highest positive both phenotypic and genotypic direct effect on grain yield were exerted by days to heading followed by panicle length and number of filled grain per panicle. In contrast, high order of negative both phenotypic and genotypic indirect effects were extended by panicle length on grain yield via days to maturity $(-0.167)$, thousand seed weight $(-0.162)$ and plant height (-0.09). The direct effects of the remaining six characters were too low to be considered important and the rest of the estimates of indirect effects obtained in path analysis were negligible. Generally, it can be concluded that there is a favorable situation for obtaining high response to selection in improving yield and its components in upland rice.
\end{abstract}

KEYWORDS: Upland rice, Correlations coefficients, Path coefficient analysis

\section{INTRODUCTION}

Rice is belonging to the grass species Oryza glaberrima (African rice) or Oryza sativa (Asian rice). As a cereal grain, it is the most widely consumed staple food for a large part of the world's human population, especially in Asia and Africa. It is the agricultural commodity with the third-highest worldwide production (rice, 741.5 million tonnes in 2014), after sugarcane (1.9 billion tonnes) and maize (1.0 billion tonnes) (FAOSTAT, 2020). Identification of important yield components and information about the nature and magnitude of their direct and indirect contributions towards the manifestation of grain yield is very essential for devising successful crop breeding strategy in any crop. The correlation and path-coefficient analysis provide information about the relative importance of various yield components in the expression of yield and thus, help in formation of appropriate selection strategy.

Path coefficient analysis partitions the genetic correlation between yield and its component traits into direct and indirect effects and hence has effectively been used in identifying useful traits as selection criteria to improve grain yield in rice (Akinwale et al., 2011; Sadeghi, 2011). Grain yield has been reported to be influenced by high direct positive effects of productive tillers, days to flowering and grains per panicle (Sadeghi, 2011), filled grains per panicle (Hairmansis et al., 2010), panicles per plant and grains per panicle (Mustafa \& Elsheikh, 2007; Akinwale et al., 2010), panicles per panicle, grains per panicle, plant height and days to flowering (Kole et al., 2008). 
Enriching genetic resources and understanding the magnitude of variability present and association of various agro-morphological characters with grain yield is of paramount importance before initiating a breeding program. The present study was under taken with an objective of studying the genetic variability, character association and phenotypic and genotypic path coefficient analysis in upland rice genotypes in northwest part of Ethiopia particularly at Pawe condition.

\section{MATERIALS AND METHODS}

The experimental material for the present investigation consisted of 16 genotypes including check varieties NERICA-4 which were obtained from Africa Rice and IRRI (Table 1). The experiment was conducted at Pawe agricultural research center on station and village -14 during 2016-2017 main cropping season. The experiment was conducted in 2 consecutive seasons. These two seasons was considered as two environments viz, E1 and E2 for the experiments. The experiment was conducted in randomized complete block design with three replications. The entries were grown in $5 \mathrm{~m}$ long by $1.5 \mathrm{~m}$ width in six rows with a spacing of $25 \mathrm{~cm}$ between rows. The space between block and between plots were $2 \mathrm{~m}$ and $50 \mathrm{~cm}$ respectively. Recommended agronomic practices were done. Five competitive plants from each plot were randomly selected for recording data on plant height, panicle length, number of fertile and non-fertile tillers, number of filled and unfilled grains per panicle. Count data, days to $50 \%$ heading, days to $85 \%$ maturity, stand count, 1000 seed weight $(\mathrm{g})$, biological yield(kg/ha), grain yield( $\mathrm{kg} / \mathrm{ha})$. Seeds were also adjusted to a moisture level of $14 \%$ using moisture content tester and then converted into $\mathrm{kg} \mathrm{ha}^{-1}$. The weight of thousand grains (TGW) from the grain yield of each plot was determined using a sensitive balance machine. The data recorded were subjected to the phenotypic Pearson correlation analysis among different characters was carried out as per procedure suggested by Searle (1961) and path coefficient analysis was carried out as formulated by Dewey and Lu (1959).

\section{RESULTS AND DISCUSSION}

\section{Phenotypic and Genotypic Correlation Coefficients}

The estimates of phenotypic and genotypic correlation coefficients computed between nine characters were presented in Table 2. Days to maturity exhibited highly significant $(\mathrm{P}<0.001)$ and positive phenotypic correlation with days to heading $(0.77)$ followed by plant height with days to heading $(0.70)$. Number of

Table 1: List of genotypes used for this experiment

\begin{tabular}{lll}
\hline No.Pedigree name & No.Pedigree name \\
\hline 1 & Hidasse (WAB515-B-16A1-2) & 9 NERICA-12 \\
2 & Getachew (AD01) & 10 NERICA-13 \\
3 & Andassa (AD012) & 11 ACCU16Bar-12-12-16-3-B-B) \\
4 & Tana (AD048) & 12 Upland NERICA-15 \\
5 & NERICA-3(WAB-450-IB-P-28-HB) & 13 Upland NERICA-18 \\
6 & NERICA-4 (WAB-450-IB-P-9/1) & 14 FOFIFA-4129 \\
7 & SUPERICA-1(WAB-4507) & 15 FOFIFA-3737 \\
8 & Kokit (IRAT-209) & 16 FOFIFA-3730 \\
\hline
\end{tabular}

filled grains per panicle (0.63) and had positive and significant association with number of fertile tillers. Number of fertile tillers showed highly significant and positive phenotypic correlation with plant height $(0.58)$ and also number of filled grains with panicle length (0.56). Grain yield had positive and significant phenotypic correlation with number of filled grains (0.51).

The estimates of genotypic correlation coefficients between nine characters presented in Table 2, were generally different in sign but higher in magnitude than the corresponding phenotypic correlation coefficients. Days to maturity and plant height were showed strong positive and significant $(\mathrm{P}<0.001)$ genotypic correlations with days to $50 \%$ heading $(0.92)$ and $(0.83)$, respectively. Plant height had positive and significant genotypic correlation with days to maturity (0.70). Number of fertile tillers was showed positive and significant genotypic correlation with plant height (0.73). Grain yield also had positive and significant genotypic correlation with number of filled grains per panicle (0.71).

\section{Correlation Coefficients}

In the present investigation, phenotypic and genotypic correlation coefficients was computed among nine characters (Table 3). Days to maturity and plant height showed highly significant and positive phenotypic correlation and very high order positive genotypic correlation with days to $50 \%$ heading. Number of fertile tillers per plant showed highly significant and positive phenotypic and high order positive genotypic association with plant height. Grain yield showed high significant and positive phenotypic correlation and high order positive genotypic association with number of filled grains per panicle and panicle length. Therefore, days to maturity, plant height and number of fertile tillers per plant emerged as most important associates of grain yield in rice under upland conditions. The strong positive and significant genotypic and phenotypic correlation of days to maturity and plant height with days to $50 \%$ heading indicating that the present of long/ short days to heading directly have long/short days to maturity and plant height. Solomon and Wegary, (2016) reported similar results by evaluated 10 Ethiopian upland rice varieties studied under lowland condition. The strong positive associations of grain yield with number of filled grain per panicle and panicle length. Therefore, yield can be improved through the production of a good number of filled grains per panicle and increasing the size of panicle length by appropriate agronomic management practice. Similar findings have been reported in rice by many scientists (Akinwale et al., 201 1; Karim et al., 2014; Islam et al., 2015; Ratana et al., 2015; Prakash et al., 2018; Akter et al., 2018).

The phenotypic and genotypic correlation coefficients also presented in Table 3. Thousand seed weight was showed significant and high positive phenotypic and genotypic correlation coefficients with days to maturity and positive phenotypic correlation with number of unfilled grains per panicle. These results imply that thousand seed weight can be improved through selection of late maturing plant and thousand seed weight was not dependent on number of unfilled grains per panicle. This trait also negative genotypic correlation with panicle length. This result disagrees with the finding of Prakash et al. (2018). 
Table 2: Estimates of phenotypic and genotypic (indicated in bold) correlation coefficients between 9 traits in upland rice varieties on farm (village -14)

\begin{tabular}{|c|c|c|c|c|c|c|c|c|c|}
\hline Traits & $\mathrm{DM}$ & $\mathrm{PH}$ & PL & NFT & NFG & NUFG & SC & GY & TSW \\
\hline \multicolumn{10}{|l|}{$\mathrm{DH}$} \\
\hline $\mathrm{P}$ & $0.771 * * *$ & $0.701 * * *$ & 0.148 & $0.332 *$ & -0.127 & $0.43 * *$ & -0.006 & -0.112 & 0.083 \\
\hline$G$ & $0.92 * * *$ & $0.831 * * *$ & 0.106 & $0.598 * *$ & -0.157 & $0.523 *$ & -0.08 & -0.108 & 0.14 \\
\hline \multicolumn{10}{|l|}{ DM } \\
\hline$P$ & & $0.407 * * *$ & -0.054 & 0.077 & $-0.308^{*}$ & 0.274 & 0.001 & $-0.287^{*}$ & 0.125 \\
\hline G & & $0.703 * * *$ & -0.05 & 0.428 & -0.382 & $0.526^{*}$ & -0.119 & -0.255 & 0.244 \\
\hline \multicolumn{10}{|l|}{$\mathrm{PH}$} \\
\hline $\mathrm{P}$ & & & 0.31 * & $0.582 * * *$ & -0.02 & $0.378 * *$ & 0.156 & -0.04 & 0.177 \\
\hline G & & & 0.07 & $0.734 * * *$ & -0.328 & 0.352 & 0.028 & -0.264 & 0.241 \\
\hline \multicolumn{10}{|l|}{ PL } \\
\hline$P$ & & & & $0.418 * * *$ & $0.561 * * *$ & $0.629 * * *$ & $0.339 *$ & $0.489 * * *$ & -0.232 \\
\hline$G$ & & & & 0.273 & $0.604 * *$ & $0.629 * * *$ & 0.319 & $0.624 * * *$ & -0.348 \\
\hline \multicolumn{10}{|l|}{ NFT } \\
\hline$P$ & & & & & 0.126 & $0.428 * * *$ & $0.316 * *$ & 0.207 & 0.069 \\
\hline$G$ & & & & & -0.235 & 0.414 & 0.117 & -0.148 & 0.169 \\
\hline \multicolumn{10}{|l|}{$N F G$} \\
\hline$P$ & & & & & & 0.254 & 0.128 & $0.513 * * *$ & $-0.344 * *$ \\
\hline G & & & & & & 0.078 & 0.15 & $0.715 * * *$ & $-0.637 * *$ \\
\hline \multicolumn{10}{|l|}{ NUFG } \\
\hline $\mathrm{P}$ & & & & & & & 0.189 & 0.279 & 0.024 \\
\hline G & & & & & & & 0.221 & 0.213 & 0.047 \\
\hline \multicolumn{10}{|l|}{ SC } \\
\hline $\mathrm{P}$ & & & & & & & & 0.25 & -0.208 \\
\hline G & & & & & & & & 0.427 & -0.39 \\
\hline \multicolumn{10}{|l|}{ GY } \\
\hline$P$ & & & & & & & & & $-0.435^{* *}$ \\
\hline G & & & & & & & & & $-0.726 * * *$ \\
\hline
\end{tabular}

$*, * *$ and $* * *$ indicate significance at $0.05 ; 0.01$ and 0.001 probability levels, respectively. Traits: $\mathrm{DH}=\mathrm{Days}$ to $50 \%$ heading; $\mathrm{DM}=\mathrm{Days}$ to maturity; $\mathrm{PH}=\mathrm{Plant}$ height $(\mathrm{cm}) ; \mathrm{PL}=$ Panicle length $(\mathrm{cm}) ; \mathrm{NFT}=$ Number of fertile tillers; NFG $=$ Number of filled grains per panicle; $N U F G=$ Number of unfilled grains per panicle; $\mathrm{SC}=\mathrm{Stand}$ count and $\mathrm{G} Y=\mathrm{G}$ rain yield $(\mathrm{kg} / \mathrm{ha})$.

These results revealed that long height rice plants produced longer panicle length and panicle length was not dependent on days to maturity. This result in the contrary of Chaubey and Singh (1994) findings on the positive association of panicle length with days to maturity.

In the present study, majority of significant estimates of correlations between yield and yield components were positive in nature. Out of 20 significant estimates among the total 45 correlations obtained between different character pairs, 16 correlation coefficients were positive in nature, while, 4 estimates were negative. This represents highly favorable situation for obtaining high response to selection in improving yield and yield components in rice. Thus, selection practiced for improving these traits individually or simultaneously would bring improvement in other due to correlated response. This suggested that selection would be quite efficient in improving yield and yield components.

\section{Path Coefficient Analysis}

The direct and indirect effects of nine characters on grain yield per hectare estimated by path coefficient analysis using genotypic correlations on station were given in Table 4.

The highest positive direct effect on grain yield was exerted by days to $50 \%$ heading $(0.344)$ followed by number of filled grain per panicle (0.308) and panicle length (0.283). The direct effects of remaining six characters were too low to be considered important. Panicle length exhibited high order of positive indirect effects on grain yield via plant height (0.191) followed by number of filled grain per panicle via number of unfilled grains per panicle $(0.121)$ and number of filled grain per panicle via panicle length (0.103). In contrast, high order of negative indirect effects was extended by panicle length on grain yield per hectare via days to maturity (-0.167) and thousand seed weight (-0.162). Days to $50 \%$ heading and number of filled grain per panicle exhibited high order of negative indirect effects on grain yield via stand count at harvest $(-0.106)$ and thousand seed weight $(-0.105)$, respectively. The rest of the estimates of indirect effects obtained in path analysis were negligible or less important.

The direct and indirect effects of nine characters on grain yield per hectare estimated by path coefficient analysis using phenotypic correlations on station are given in Table 5. The highest positive direct effect on grain yield was exerted by number of filled grain per panicle $(0.235)$ followed by plant height (0.223) and days to 50\% heading (0.151). The direct effects of remaining six characters were too low to be considered important. Plant height exhibited high order of positive indirect effects on grain yield via panicle length $(0.108)$ and number of filled grains per panicle (0.069). Number of filled grain per panicle also exhibited high order of positive indirect effects on grain yield via number of unfilled grains per panicle (0.064). In contrast, high order of negative indirect effects was extended 
Table 3: Estimates of phenotypic and genotypic (indicated in bold) correlation coefficients between 9 traits in upland rice varieties on station

\begin{tabular}{|c|c|c|c|c|c|c|c|c|c|}
\hline Traits & $\mathrm{DM}$ & $\mathrm{PH}$ & PL & NFT & NFG & NUFG & SC & $G Y$ & TSW \\
\hline DH & -0.07 & 0.212 & 0.181 & 0.153 & 0.225 & 0.1 & -0.267 & 0.229 & 0.073 \\
\hline $\begin{array}{l}P \\
G\end{array}$ & -0.146 & 0.102 & 0.183 & 0.15 & 0.272 & 0.248 & -0.309 & 0.414 & 0.076 \\
\hline $\mathrm{DM}$ & & -0.14 & $-0.301 *$ & 0.209 & -0.091 & 0.262 & -0.145 & -0.24 & $0.444 * * *$ \\
\hline $\begin{array}{l}P \\
G\end{array}$ & & -0.314 & $-0.592^{* *}$ & 0.049 & -0.311 & 0.33 & -0.263 & -0.268 & $0.752 * * *$ \\
\hline $\mathrm{PH}$ & & & $0.486 * * *$ & 0.152 & $0.309 *$ & -0.153 & 0.168 & 0.216 & -0.124 \\
\hline $\begin{array}{l}P \\
G\end{array}$ & & & $0.676 * *$ & 0.13 & 0.283 & -0.028 & 0.17 & 0.213 & -0.401 \\
\hline PL & & & & 0.088 & 0.236 & -0.107 & 0.184 & 0.026 & -0.21 \\
\hline $\begin{array}{l}P \\
G\end{array}$ & & & & -0.175 & 0.333 & -0.254 & 0.328 & 0.447 & $-0.574^{*}$ \\
\hline NFT & & & & & 0.123 & -0.047 & -0.12 & -0.156 & -0.016 \\
\hline $\begin{array}{l}P \\
G\end{array}$ & & & & & 0.063 & -0.132 & -0.029 & -0.307 & -0.025 \\
\hline$N F G$ & & & & & & 0.272 & 0.129 & 0.26 & -0.17 \\
\hline $\begin{array}{l}P \\
G\end{array}$ & & & & & & 0.394 & 0.003 & 0.464 & -0.342 \\
\hline NUFG & & & & & & & -0.249 & -0.018 & $0.357 * *$ \\
\hline $\begin{array}{l}P \\
G\end{array}$ & & & & & & & -0.477 & 0.197 & 0.422 \\
\hline SC & & & & & & & & -0.102 & -0.262 \\
\hline $\begin{array}{l}P \\
G\end{array}$ & & & & & & & & -0.04 & -0.468 \\
\hline $\begin{array}{r}G Y \\
P \\
G\end{array}$ & & & & & & & & & $\begin{array}{l}-0.174 \\
-0.215\end{array}$ \\
\hline
\end{tabular}

$*, * *$ and $* * *$ indicate significance at $0.05 ; 0.01$ and 0.001 probability levels, respectively. Traits: $\mathrm{DH}=$ Days to $50 \%$ heading; $\mathrm{DM}=\mathrm{Days}$ to maturity; $\mathrm{PH}=$ Plant height $(\mathrm{cm}) ; \mathrm{PL}=$ Panicle length $(\mathrm{cm}) ; \mathrm{NFT}=$ Number of fertile tillers; NFG $=$ Number of filled grains per panicle; $N U F G=N u m b e r$ of unfilled grains per panicle; $S C=S$ tand count; $G Y=G$ rain yield $(\mathrm{kg} / \mathrm{ha}) ; P=$ Phenotypic coefficient of correlation and $G=$ Genotypic coefficient of correlation.

Table 4: Estimates of genotypic direct and indirect effects of 9 traits on grain yield in upland rice varieties at on station

\begin{tabular}{|c|c|c|c|c|c|c|c|c|c|}
\hline Traits & $\mathrm{DH}$ & $\mathrm{DM}$ & $\mathrm{PH}$ & $\mathrm{PL}$ & NFT & $N F G$ & NUFG & SC & TSW \\
\hline DH & $0.344 *$ & -0.017 & -0.006 & 0.052 & -0.050 & 0.084 & 0.001 & 0.015 & -0.009 \\
\hline DM & -0.050 & $0.118^{*}$ & 0.019 & -0.167 & -0.016 & -0.096 & 0.002 & 0.013 & -0.090 \\
\hline $\mathrm{PH}$ & 0.035 & -0.037 & $-0.060 *$ & 0.191 & -0.043 & 0.087 & 0.000 & -0.008 & 0.048 \\
\hline$P L$ & 0.063 & -0.070 & -0.040 & $0.283 *$ & 0.058 & 0.103 & -0.001 & -0.016 & 0.069 \\
\hline NFT & 0.052 & 0.006 & -0.008 & -0.049 & $-0.330 *$ & 0.019 & -0.001 & 0.001 & 0.003 \\
\hline NFG & 0.094 & -0.037 & -0.017 & 0.094 & -0.021 & $0.308^{*}$ & 0.002 & 0.000 & 0.041 \\
\hline NUFG & 0.085 & 0.039 & 0.002 & -0.072 & 0.044 & 0.121 & $0.005^{*}$ & 0.024 & -0.050 \\
\hline SC & -0.106 & -0.031 & -0.010 & 0.093 & 0.010 & 0.001 & -0.002 & $-0.049 *$ & 0.056 \\
\hline TSW & 0.026 & 0.089 & 0.024 & -0.162 & 0.008 & -0.105 & 0.002 & 0.023 & -0.120 * \\
\hline
\end{tabular}

Residual effect: 0.0584 , *Direct effects on main diagonal. Traits: $\mathrm{DH}=$ Days to $50 \%$ heading; DM =Days to maturity; $\mathrm{PH}=\mathrm{Plant}$ height (cm);

$\mathrm{PL}=$ Panicle length $(\mathrm{cm}) ; \mathrm{NFT}=$ Number of fertile tillers; NFG $=$ Number of filled grains per panicle; NUFG $=$ Number of unfilled grains per panicle; $\mathrm{SC}=\mathrm{Stand}$ count and $\mathrm{GY}=\mathrm{Grain}$ yield $(\mathrm{kg} / \mathrm{ha})$.

Table 5: Estimates of phenotypic direct and indirect effects of 9 traits on grain yield in upland rice varieties at on station

\begin{tabular}{|c|c|c|c|c|c|c|c|c|c|}
\hline Traits & $\mathrm{DH}$ & DM & $\mathrm{PH}$ & $\mathrm{PL}$ & NFT & NFG & NUFG & SC & TSW \\
\hline DH & $0.151 *$ & 0.010 & 0.047 & -0.034 & -0.034 & 0.053 & -0.006 & 0.051 & -0.009 \\
\hline DM & -0.011 & $-0.142^{*}$ & -0.031 & 0.056 & -0.047 & -0.021 & -0.015 & 0.027 & -0.056 \\
\hline $\mathrm{PH}$ & 0.032 & 0.020 & $0.223 *$ & -0.090 & -0.034 & 0.073 & 0.009 & -0.032 & 0.016 \\
\hline$P L$ & 0.027 & 0.043 & 0.108 & $-0.186^{*}$ & -0.020 & 0.055 & 0.006 & -0.035 & 0.026 \\
\hline NFT & 0.023 & -0.030 & 0.034 & -0.016 & $-0.223 *$ & 0.029 & 0.003 & 0.023 & 0.002 \\
\hline$N F G$ & 0.034 & 0.013 & 0.069 & -0.044 & -0.027 & $0.235^{*}$ & -0.016 & -0.024 & 0.021 \\
\hline NUFG & 0.015 & -0.037 & -0.034 & 0.020 & 0.010 & 0.064 & $-0.058^{*}$ & 0.047 & -0.045 \\
\hline SC & -0.040 & 0.021 & 0.037 & -0.034 & 0.027 & 0.030 & 0.014 & $-0.189 *$ & 0.033 \\
\hline TSW & 0.011 & -0.063 & -0.027 & 0.039 & 0.004 & -0.040 & -0.021 & 0.050 & $-0.126^{*}$ \\
\hline
\end{tabular}

Residual effect: 0.0584 , Direct effects on main diagonal. Traits: $\mathrm{DH}=$ Days to $50 \%$ heading; $\mathrm{DM}=$ Days to maturity; $\mathrm{PH}=\mathrm{Plant}$ height (cm); $\mathrm{PL}=$ Panicle length $(\mathrm{cm}) ; \mathrm{NFT}=$ Number of fertile tillers; $\mathrm{NFG}=$ Number of filled grains per panicle; $N U F G=$ Number of unfilled grains per panicle; $\mathrm{SC}=\mathrm{Stand}$ count and $\mathrm{GY}=\mathrm{Grain}$ yield $(\mathrm{kg} / \mathrm{ha})$ 
by panicle length on grain yield via plant height (-0.090). Days to maturity exhibited high order of negative indirect effect on grain yield via thousand seed weight $(-0.063)$ and thousand seed weight via days to maturity $(-0.056)$. The rest of the estimates of indirect effects obtained in path analysis were too low to be considered as important.

\section{Path Coefficient Analysis}

Path coefficient analysis is a tool to partition the observed correlation coefficient into direct and indirect effects of yield components on grain yield. Path analysis provides clearer picture of character associations for formulating efficient selection strategy. Path coefficient analysis differs from simple correlation in that it points out the causes and their relative importance, whereas, the later measures simply the mutual association ignoring the causation. The concept of path coefficient was developed by Wright, (1960) and technique was first used for plant selection by Dewey and Lu, (1959). Path analysis has emerged as a powerful and widely used technique for understanding the direct and indirect contributions of different characters to economic yield in crop plants so that the relative importance of various yield contributing characters can be assessed.

In the present study, the path coefficient analysis was carried out using phenotypic and genotypic correlation coefficients between nine characters on both on station and on farm level as indicted in Table 4, 5, 6 and 7.

\section{Path Coefficient Analysis on Station Level}

The very high positive direct effects on grain yield per hectare were exerted by days of $50 \%$ heading followed by number of filled grain per panicle at both genotypic and phenotypic level (Table 4, 5). Panicle length and days to maturity also showed high positive direct genotypic correlation and plant height exhibited high positive phenotypic direct effect on grain yield. Thus, days to $50 \%$ heading and number of filled grain per panicle emerged as most important direct yield components on which emphasis should be given during simultaneous selection aimed at improving grain yield in upland rice. In addition, panicle length, days to maturity and plant height also considered important contributor for improvement of grain yield of upland rice next to days to heading and number of filled grain per panicle. These characters have also been identified as major direct contributors towards grain yield (Karim et al., 2014; Dhurai et al., 2016). The direct effects of remaining four traits were too low to be considered important contributors for rice grain yield improvement program.

Number of filled grain per panicle exhibited very high order positive genotypic and phenotypic indirect effects on grain yield via panicle length, number of unfilled grains per panicle and days to heading (Table 4, 5). Panicle length also exhibited high order of positive genotypic and phenotypic indirect effects on grain yield. These implies number of filled grain per panicle and panicle length were the major indirect effects contributors for improvement of upland rice grain yield. The rest of the indirect effects contributed to low for rice grain yield improvement program (Roy et al., 2015; Solomon and Wegary, 2016).

Table 6: Estimates of genotypic direct and indirect effects of 9 traits on grain yield in upland rice varieties on farm (village-14)

\begin{tabular}{|c|c|c|c|c|c|c|c|c|c|}
\hline Traits & $\mathrm{DH}$ & $\mathrm{DM}$ & $\mathrm{PH}$ & PL & NFT & NFG & NUFG & SC & TSW \\
\hline DH & $2.867^{*}$ & -1.992 & -0.738 & 0.082 & -0.391 & 0.148 & 0.006 & -0.015 & -0.075 \\
\hline DM & 2.638 & $-2.165^{*}$ & -0.625 & -0.038 & -0.279 & 0.361 & 0.006 & -0.022 & -0.131 \\
\hline $\mathrm{PH}$ & 2.383 & -1.522 & $-0.888^{*}$ & 0.054 & -0.479 & 0.309 & 0.004 & 0.005 & -0.129 \\
\hline PL & 0.304 & 0.108 & -0.062 & $0.770^{*}$ & -0.178 & -0.571 & 0.007 & 0.058 & 0.187 \\
\hline NFT & 1.716 & -0.926 & -0.652 & 0.210 & $-0.654^{*}$ & 0.222 & 0.004 & 0.021 & -0.091 \\
\hline$N F G$ & -0.449 & 0.828 & 0.291 & 0.465 & 0.154 & $-0.944 *$ & 0.001 & 0.027 & 0.342 \\
\hline NUFG & 1.499 & -1.139 & -0.313 & 0.484 & -0.271 & -0.073 & $0.011^{*}$ & 0.04 & -0.025 \\
\hline SC & -0.229 & 0.257 & -0.024 & 0.246 & -0.076 & -0.141 & 0.002 & $0.183 *$ & 0.21 \\
\hline TSW & 0.401 & -0.528 & -0.214 & -0.268 & -0.111 & 0.601 & 0.001 & -0.072 & $-0.537^{*}$ \\
\hline
\end{tabular}

Residual effect: 0.0584 , Direct effects on main diagonal. Traits: DH=Days to $50 \%$ heading; $\mathrm{DM}=$ Days to maturity; $\mathrm{PH}=\mathrm{Plant}$ height (cm); $P L=$ Panicle length (cm); NFT = Number of fertile tillers; NFG $=$ Number of filled grains per panicle; NUFG $=$ Number of unfilled grains per panicle; $\mathrm{SC}=\mathrm{Stand}$ count and $\mathrm{G} Y=\mathrm{Grain}$ yield $(\mathrm{kg} / \mathrm{ha})$

Table 7: Estimates of phenotypic direct and indirect effects of 9 traits on grain yield in upland rice varieties on farm (village-14)

\begin{tabular}{|c|c|c|c|c|c|c|c|c|c|}
\hline Traits & $\mathrm{DH}$ & DM & $\mathrm{PH}$ & PL & NFT & NFG & NUFG & SC & TSW \\
\hline DH & $0.117^{*}$ & -0.203 & -0.103 & 0.024 & 0.038 & -0.025 & 0.063 & 0.000 & -0.023 \\
\hline DM & 0.090 & $-0.263^{*}$ & -0.060 & -0.009 & 0.009 & -0.060 & 0.040 & 0.000 & -0.035 \\
\hline $\mathrm{PH}$ & 0.082 & -0.107 & $-0.146^{*}$ & 0.051 & 0.066 & -0.004 & 0.056 & 0.011 & -0.049 \\
\hline$P L$ & 0.017 & 0.014 & -0.045 & $0.165^{*}$ & 0.047 & 0.110 & 0.093 & 0.024 & 0.064 \\
\hline NFT & 0.039 & -0.020 & -0.085 & 0.069 & $0.113 *$ & 0.025 & 0.063 & 0.023 & -0.019 \\
\hline$N F G$ & -0.015 & 0.081 & 0.003 & 0.092 & 0.014 & $0.196 *$ & 0.037 & 0.009 & 0.095 \\
\hline NUFG & 0.050 & -0.072 & -0.055 & 0.104 & 0.048 & 0.050 & $0.147^{*}$ & 0.014 & -0.007 \\
\hline SC & -0.001 & 0.000 & -0.023 & 0.056 & 0.036 & 0.025 & 0.028 & $0.072^{*}$ & 0.058 \\
\hline TSW & 0.010 & -0.033 & -0.026 & -0.038 & 0.008 & -0.067 & 0.004 & -0.015 & $-0.276^{*}$ \\
\hline
\end{tabular}

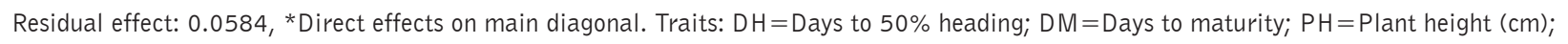
$\mathrm{PL}=$ Panicle length $(\mathrm{cm}) ; \mathrm{NFT}=$ Number of fertile tillers; $N F G=$ Number of filled grains per panicle; NUFG $=$ Number of unfilled grains per panicle; $\mathrm{SC}=\mathrm{Stand}$ count and $\mathrm{GY}=\mathrm{Grain}$ yield $(\mathrm{kg} / \mathrm{ha})$ 


\section{Path Coefficient Analysis at on Farm Level}

Days to heading, panicle length, stand count at harvest and number of unfilled grains per panicle exhibited high order of positive genotypic direct effects on grain yield (Table 6). But number of filled grain per panicle, panicle length, number of unfilled grains per panicle and number of fertile tillers per plant exhibited very high order of positive phenotypic direct effects on grain yield (Table 7). Therefore, days to heading, number of filled and unfilled grains per panicle, panicle length and number of tillers per plant were identified as very important direct grain yield contributing characters for improving future upland rice breeding program. Many scientists improved these traits also the main direct yield contributors (Karim et al., 2014; Roy et al., 2015; Solomon and Wegary, 2016; Oladosu et al., 2018).

Days to heading exhibited very high order positive genotypic indirect effects on grain yield via days to maturity, plant height, number of fertile tillers, and number of unfilled grains per panicle (Table 6). However, number of filled grain, thousand seed weight, panicle length exhibited very high order of positive phenotypic indirect effects on grain yield via panicle length, number of filled grains per panicle and panicle length via number of unfilled grains per panicle and number of filled grains per panicle (Table 7). Days to heading, number of filled grains per panicle, thousand seed weight and panicle length were identified as important indirect yield contributing characters (Roy et al., 2015; Manohara and Singh, 2015; Oladosu et al., 2018). The indirect effects of remaining characters were too low to be considered important.

\section{CONCLUSION}

Present investigation revealed that characters such as days to heading, panicle length and number of filled grains per panicle are the important yield determinant components which have been showed significant and positive association with grain yield. However, path analysis study revealed that characters viz., days to heading, panicle length and number of filled grain per panicle exhibited high correlation with grain yield through their high positive direct effect. Hence, selection based on above three characters would be most effective under upland condition for enhancing the grain yield of rice.

\section{REFERENCES}

Akinwale, M. G., Gregorio, G., Nwilene, F., Akinyele, B. O., Ogunbayo, S. A., \& Odiyi, A.C., (2011). Heritability and correlation coefficient analysis for yield and its components in rice (Oryza sativa L.). African Journal of Plant Science, 5(3), 207-212.

Akter, N., Khalequzzaman, M., \& Islam, M. Z. (2018). Genetic variability and character association of quantitative traits in Jhum. SAARC Journal of Agriculture, 16(1), 193-203. https://doi.org/10.3329/sja.v16i1.37434

Chaubey, P. K., \& Singh, R. P. (1994). Genetic variability, correlation and path analysis of yield components of rice. Madras Agricultural Journal, $81,468-70$.

Dewey, D. I. \& Lu, K. H. (1959). A Correlation and Path-Coefficient Analysis of Components of Crested Wheatgrass Seed Production. Agronomy Journal, 51(9), 515-518. https://doi.org/10.2134/agronj1959.000219 $62005100090002 x$

Dhurai S. Y., Reddy, D. M., \& Ravi, S. (2016). Correlation and Path Analysis for Yield and Quality Characters in Rice (Oryza sativa L.). Rice Genomics and Genetics, 7(4), 1-6.

FAOSTAT. (2020). Statistical database. Food and Agriculture Organizations of the United Nations.

Hairmansis, A., Kustianto, B., \& Suwarno, S. (2010). Correlation analysis of agronomic characters and grain yield of rice for tidal swamp areas. Indonesian Journal of Agricultural Science, 11(1), 11-15. https://doi. org/10.21082/ijas.v11n1.2010.p11-15

Islam, M. A., Raffi, S. A., Hossain, M. A., \& Hasan, A. K. (2015). Analysis of genetic variability, heritability and genetic advance for yield and yield associated traits in some promising advanced lines of rice. Progressive Agriculture, 26(1), 26-31. https://doi.org/10.3329/ pa.v26i1.24511

Karim, D., Siddique, N., \& Sarkar, U. (2014). Phenotypic and genotypic correlation co-efficient of quantitative characters and character association of aromatic rice. Journal of Bioscience and Agricultural Research, 01(01), 34-46. https://doi.org/10.18801/jbar.010114.05

Manohara, K. K., \& Singh, N. (2015). Genetic variability, Correlation and Path analysis in Rice (Oryza sativa L.) under coastal salinity conditions of Goa. Journal of the Indian Society of Coastal Agricultural Research, 33(1), 34-39

Oladosu, Y., Rafii, M. Y., Magaji, U., Abdullah, N., Miah, G., Chukwu, S. C., Hussin, G., Ramli, A., \& Kareem, I. (2018). Genotypic and Phenotypic Relationship among Yield Components in Rice under Tropical Conditions. Biomed Research International, 8936767, 1-10. https:// doi.org/10.1155/2018/8936767

Prakash, H. P., Verma, O. P., \& Chaudhary, A. K. (2018). Correlation and Path Coefficient Analysis in Rice (Oryza sativa L.) for Sodicity Tolerance. International Journal of Current Microbiology and Applied Sciences, 7(07), 177-187. https://doi.org/10.20546/ijcmas.2018.707.022

Ratana, M., Begum, S., Husna, A., Dey, S. R., \& Hossain, M. S. (2015). Correlation and path coefficients analyses in basmati rice. Bangladesh Journal of Agricultural Research, 40(1) 153-161. https://doi. org/10.3329/bjar.v40i1.23768

Roy, K. R., Majumder, R. R., Shahanaz, S., Hoque, M., \& Ali, M. (2015). Genetic variability, correlation and path coefficient analysis for yield and yield components in transplant aman rice (Oryza sativa L.). Bangladesh Journal of Botany, 44, 529-535. https://doi.org/10.3329/ bjb.v44i4.38566

Sadeghi, S. M. (2011). Heritability, phenotypic correlation and path coefficient studies for some agronomic characters in landrace rice varieties. World Applied Sciences Journal, 13(5), 1229-1233.

Searle, S. R. (1961). Phenotypic, Genotypic and Environmental correlations Biometrics 17, 474-480. https://doi.org/10.2307/2527838

Solomon, H., \& Wegary, D. (2016). Phenotypic Correlation and Path Coefficient Analysis of Yield and Yield Component in Rice (Oryza Sativa). International Journal of Research and Review, 3(7), 1-5.

Wright, S. (1960). Path coefficients and path regressions: alternative or complementary concepts? Biometrics, 16, 189-202. https://doi org/10.2307/2527551 